\title{
Acid-base properties and structons: towards a structural model for predicting the thermodynamic properties of silicate melts
}

\author{
Donald G. Fraser \\ Department of Earth Sciences, University of Oxford, U.K.
}

\begin{abstract}
Phase equilibrium relationships in igneous systems can be estimated using empirical mathematical models based on multi-component regular solution formulae. Although these provide useable results within the fitted region, they can give very misleading values outside the compositional range of curve fitting. Moreover, they usually give poor estimates of the well-characterized melting relations of simple systems and do not relate to the large body of thermodynamic activity data available in the metallurgical literature, nor to spectroscopic, diffraction or computational models of silicate melt properties. The aim of this paper is to extend previous acid-base models of silicate melts and to use a quasi-chemical model to calculate the activities of quasi-chemical silicate mixing units, or structons, from combinations of the oxo-species used in quasi-chemical and polymer models to calculate oxide activities in metallurgy.
\end{abstract}

Key words silicate melt - acid-base - oxide meltthermodynamic properties

\section{Introduction}

In extraction metallurgy, quasi-chemical (Toop and Samis, 1962a,b) and polymer models (Masson 1965, 1972) have been used with considerable success to express the variation with melt composition and temperature of metal oxide activities in silicate melts. The aim of such calculations is to interpret the thermodynamic properties of the melts and to allow modelling of the activities of oxide components so as to maximize refining efficiency by minimizing metal loss in slags and by optimizing the physico-chemical conditions required for smelting.

Mailing address: Dr. Donald G. Fraser, Department of Earth Sciences, University of Oxford, Parks Road, Oxford OX13PR, U.K.; e-mail: Donald.Fraser@earth.ox.ac.uk
In contrast, in the earth sciences, most problems involving silicate liquids, at least in the outer part of the Earth, require knowledge of the behaviour, not of oxide constituents, but of the activities and chemical potentials of silicate species. The requirements are to provide a framework for understanding crystal-liquid equilibria over a wide range of pressure, temperature, gas and melt compositions and to include accurate descriptions of other thermodynamic properties such as density, viscosity and surface tension, again over a wide range of $P$, $T, X$.

These problems have been tackled until now mainly by fitting a large number of parameters to empirical or semi-empirical thermodynamic models (e.g., Berman and Brown 1984; Ghiorso and Sack, 1995; Ghiorso et al., 2002). In these models, the excess free energy of mixing of components is usually expressed by a particular functional form, such as that of the regular solution model, and the coefficients of the variables are fitted using calorimetric and 
phase equilibrium data for the compositional range of interest.

Thus, in an $n$-component system,

$$
\sum_{i=1}^{n} \nu_{i}\left[\mu_{i \text { liq }}^{0}+R T \ln \left(X_{i}^{\mathrm{liq}} \gamma_{i}^{\mathrm{liq}}\right)\right]=\mu_{\mathrm{solid}}^{0}+R T \ln a_{\text {solid }}
$$

where $v_{i}$ are the stoicheiometric coefficients. The various parameters must be fitted for each component $i$.

This mathematical curve fitting approach can provide usable results within the range of compositions for which the parameters are fitted although inaccurate results are obtained for certain compositions, particular those rich in $\mathrm{Na}$ (e.g., Asimow et al., 2001). The calculated data agree particularly poorly with the basic binary and ternary phase diagrams of igneous petrology for which so many primary measurements are available. An important and usually un-stated reason for the success of these polynomial curve-fits is that they deal with the limited polymerised region of composition-space which is energetically rather homogeneous that is, it excludes those basic compositions which show most of the high-energy interac-

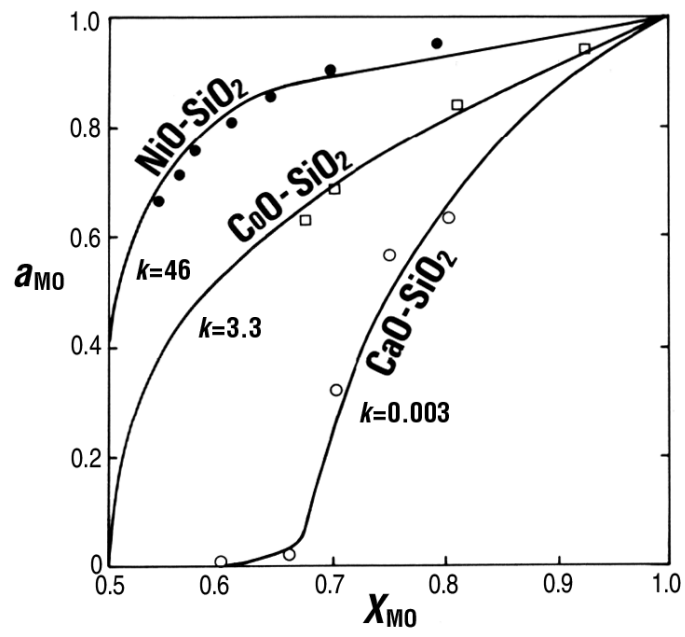

Fig. 1. Experimental measurements of oxide activities in binary silicate melts. Also shown are curves calculated using a bi-functional linear polymer model (see below). tions of $\mathrm{MO}$ and $\mathrm{SiO}_{2}$ (see fig. 1). Thus, although geologically useful, the models behave poorly in the very compositional region which is most sensitive to changes in the acid-base properties of the melts and which provides most fundamental information about their properties and the true effects of different metal ions. They are certainly not based on the knowledge of the structures and properties of the liquids. The models are therefore unreliable for extrapolation beyond the range for which they are fitted and, especially, provide little insight into the underlying properties and behaviour of silicate melts. The question of the acid-base properties of silicate melts (Duffy and Ingram, 1971) and of how to relate thermodynamic properties to structure (Fraser, 1977) has recently been revisited in an attempt to discover the factors which determine the values of the empirical coefficients for components in $\mathrm{CaO}-\mathrm{MgO}-\mathrm{Al}_{2} \mathrm{O}_{3}$ $\mathrm{SiO}_{2}$ (Beckett, 2002). In addition there is renewed interest in using acid-base properties to devise a predictive thermodynamic model properly grounded on a structural basis (Fraser 1977, 2003; Ottonello, 2001, 2005) and in explaining the behaviour of altervalent elements in silicate melts (Fraser, 1975; Moretti and Ottonello, 2003).

The aim of the present paper is to examine the extensive work on oxide activities which has been done on binary $\mathrm{SiO}_{2}-\mathrm{MO}$ melts of metallurgical interest and to relate these to the distributions of silicate species in melts. These distributions reflect the fundamental properties of silicate melts and provide insight into the chemical factors such as the acid-base properties of oxides which influence crystal liquid equilibrium in igneous systems.

\section{Oxide activity measurements in binary silicate melts}

The thermochemistry of melts and slags in divalent binary systems $\mathrm{MO}-\mathrm{SiO}_{2}$ has been studied extensively (e.g., Richardson, 1956; CrippsClark et al., 1974; Navrotsky, 1995). Mixing is usually highly non-ideal and significant deviations from ideality are observed (fig. 1). The variations of oxide activity with bulk composi- 
tion have the general form of titration curves in which each basic oxide can be considered to be titrated with the acidic oxide $\mathrm{SiO}_{2}$. The differing basicities of different oxides can be seen clearly.

\section{Acid-base schemes}

Although the qualitative concept of acidic and basic oxides is familiar to geologists and dates back to Berzelius, a quantitative definition of oxide acidity and basicity was proposed by Flood and Förland (1947) following the work of Lux (1939). In aqueous systems, acidic or basic behaviour is conveniently treated using the conjugate acid-base formulation of Brönsted and Lowry

$$
\begin{aligned}
& \text { Acid }=\text { Base }+\mathrm{H}^{+} \\
& \text {e.g., } \quad \mathrm{H}_{2} \mathrm{SO}_{4}=\mathrm{HSO}_{4-}{ }^{-}+\mathrm{H}^{+} \text {. }
\end{aligned}
$$

Alternatively, and relevant to silicate melts, a Lewis acid is simply an electron acceptor e.g., $\mathrm{Al}^{3+}$ so that the Lewis acidity may be related to the Pauling electronegativity.

In non-protonic solvents like molten oxides and silicates, a different formalism is required. In the Lux-Flood system, oxide-ion, $\mathrm{O}^{2-}$, takes the place of protons in aqueous solutions. Thus, a basic oxide is a substance capable of furnishing oxide ions, and an acidic oxide is one which reacts with $\mathrm{O}^{2-}$. Thus,

$$
\begin{array}{rlrl}
\text { Base } & =\text { Acid }+\mathrm{O}^{2-} \\
\text { e.g., } & \mathrm{SiO}_{3}^{2-} & =\mathrm{SiO}_{2}+\mathrm{O}^{2-} .
\end{array}
$$

Each acid or base is therefore characterized by a defined thermodynamic dissociation or equilibrium constant. The mixing properties of silicate melts may therefore be investigated by titrating melts with $\mathrm{SiO}_{2}$, just as protonic acidbase systems are investigated by $p H$ titration.

The interpretation of these deviations from ideality has been the subject of a family of models, all of which express the non-ideality in terms of reaction between the mixing components.

Measurements of the electrical conductivities and transport properties of silicate melts
(Bockris et al., 1952a,b; Waff and Weill, 1975; Stebbins et al., 1995) have shown that, with the exception of melts containing transition-metal ions in which significant charge transfer processes may operate, conduction in the melts is entirely ionic with Faraday's Law being obeyed. Importantly, the conductance is unipolar (Bockris et al., 1952b; Bockris and Mellors, 1956) and occurs by the transport of relatively mobile cations while the anions remain stationary. Silicate melts are thus ionic liquids like other molten salts but have an immobile anion network. Interestingly, recent NMR data (Lee and Stebbins, 2003) indicate that the behaviour of cations may also be non-random and a proposal to extend the Temkin equation (Temkin, 1945) to express the different behaviour of cations of different charge is discussed below.

The non-ideality observed in the mixing properties of silicate melts when expressed as oxide components is the observable. The difficulty in its interpretation is caused by the difficulty in expressing the excess free energy of mixing (the generally negative deviation from ideality) as a function of composition.

\section{Quasi-chemical models - Temkin equation}

The regular solution model (Hildebrand and Scott, 1950) interprets the excess free energy of mixing of a solution entirely as an enthalpy of mixing and retains a purely configurational entropy of mixing. This treatment is successful for the description of mixing of similar components - e.g., cyclohexane and benzene and the mixing of some ionic solids when the anionic framework is fixed. However it becomes more difficult to express the excess functions for mixing components as the magnitude of the deviations from ideality increases. In the case of silicates, the high energies associated with making and breaking Si-O-Si or Al-O-Si bonds make it unlikely that a simple regular solution model could succeed in systems of variable stoicheiometry like melts. This is the reason for the inability of the polynomial regular solution models to deal adequately with simple systems.

Quasi-chemical models are first-order refinements of the regular solution treatment and 
use the excess free energy of mixing to form new species with mixing properties which are much closer to ideal (e.g., Guggenheim, 1952).

The choice of quasi-chemical components in the case of silicate liquids is initially complicated by the presence of a large number of different silicate anions. While silicate minerals are usually monodisperse, containing only a single type of anion (e.g., $\mathrm{SiO}_{4}{ }^{4-}$ in olivine), molten silicates contain a distribution of different polymeric silicate anions of different molecular weights and are thus polydisperse systems with statistical distributions of polymers of different molecular weight.

Vibrational spectroscopic studies of melts and glasses provide broad information on the proportions of different bonds present among

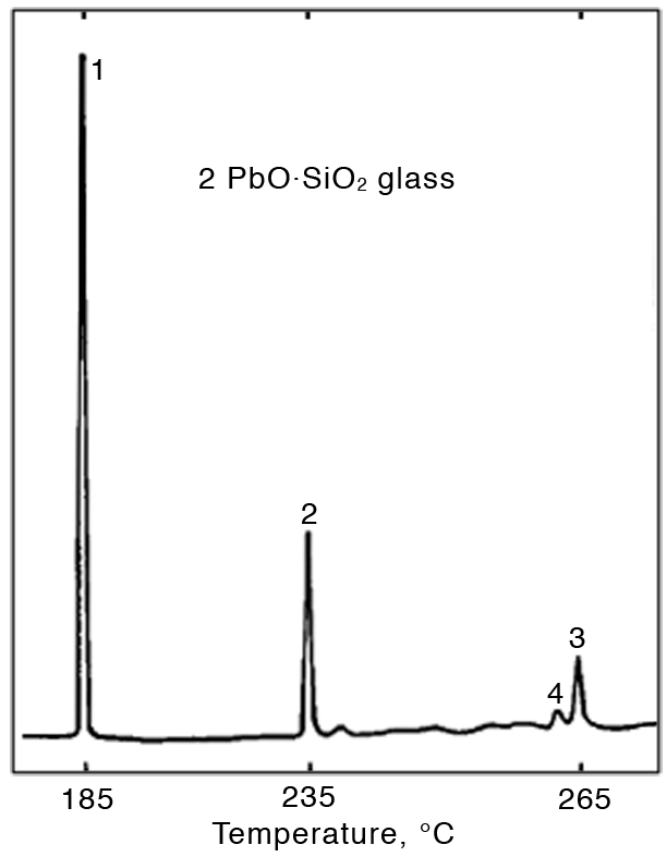

Fig. 2. Distribution of polymers in $\mathrm{Pb}_{2} \mathrm{SiO}_{4}$ glass obtained by trimethyl sliylation gas liquid chromatography of quenched glass. Temperatures refer to chromatographic separation. Peaks 1-4 represent $\mathrm{SiO}_{4}$ momomers, $\mathrm{Si}_{2} \mathrm{O}_{7}$ dimers, $\mathrm{Si}_{3} \mathrm{O}_{9}$ rings and $\mathrm{Si}_{4} \mathrm{O}_{12}$ rings respectively (after Masson, 1972). the silicate anions (e.g., Mysen, 1997). It is also possible to separate some of the different anionic species themselves using chromatographic techniques (Lentz, 1964; Götz and Masson, 1970) and even simple orthosilicate compositions like $\mathrm{Pb}_{2} \mathrm{SiO}_{4}$ contain, in the glass, a distribution of condensed polymeric species (fig. 2).

It is immediately clear from these data that even orthosilicate melts are composed not of $\mathrm{M}^{2+}$ and $\mathrm{SiO}_{4}{ }^{4-}$ ions, but rather of $\mathrm{Pb}^{2+}$ ions coordinating a distribution of anions of different molecular weight. Simple measures such as NBO/T, calculated from the overall stoicheiometry, although widely used in the geological literature, do not give this result and have been useful only because most igneous melts are more polymerised than the metasilicate composition.

Expression of the statistical nature of liquids and glasses and, in particular, the case of molten silicates, requires treatment of the energetics of all the simultaneous equilibria. Any successful treatment of the nature of silicate liquids must treat the polymerization equilibria responsible for the observed distribution of species in the melt. Similar problems exist in mixtures of organic polymers (Flory, 1936, 1953) and experience in the treatment of organic polmer melts and solutions has been of great value in developing models of molten silicates. These models deal with the complex molecular weight distributions observed by making two assumptions: 1) polymerization equilibria (i.e. the reactivities of functional groups) are independent of molecular weight and 2) Temkin mixing. The Temkin model of ionic salts (Temkin, 1945) considers the energetics of substituting cations for anions and, (essentially following the quasi-chemical approach) assumes that the energy cost of wrongly substituting a cation for an anion is sufficiently high that the probability of mixing cations and anions is zero. The correct Temkin entropy of mixing is therefore obtained by mixing anions and cations independently on sites of the anion matrix and cation matrix respectively. Recent NMR data (Lee and Stebbins, 2003) show that this is true for $\mathrm{Mg}$ and $\mathrm{Ca}$, for example, but seems not to be true for ions of different charge. Thus, whereas $\mathrm{Mg}$ and $\mathrm{Ca}$ ions mix close to randomly, $\mathrm{Na}$ and $\mathrm{Ca}$ ions occupy separate sites in the glasses studied. 
It is proposed here that for multi-component melts, the simple Temkin assumption may need to be extended to allow for this behaviour by introducing sub-matrices. The simplest would be a matrix for each valence state $M^{\mathrm{I}}, M^{\mathrm{II}}, M^{\mathrm{III}}$ and $M^{\mathrm{IV}}$. Treatment of the behaviour of $P$ and $A s$ might require a further set of exclusive sites $M^{\mathrm{V}}$. Note that the sites $M^{\mathrm{IV}}$ and $M^{\mathrm{V}}$ are probably the sites of network-forming ions and $M^{\mathrm{III}}$, at least, may be amphoteric as described below. This provides a continuity of treatment of metal ions and network forming constituents for the first time. It is analogous to the independent treatment of the entropy of mixing on different sites in solids, e.g., in $M_{3}^{\mathrm{II}} M_{2}^{\mathrm{III}} \mathrm{Si}_{3} \mathrm{O}_{12}$ garnets. The unipolar electrical conductance is determined by the very low diffusivity of highly charged ions in network-forming sites. This is supported by recent molecular dynamics calculations using a modified BKS potential which show low diffusivity of $\mathrm{Si}^{\mathrm{IV}}$ (Gemmell et al., 2003). Moreover it allows treatment of the whole melt array as an inter-related network of metal ion potential energy wells in a background of oxygen and other electronegative atoms, normally regarded as forming the «network-forming» sites.

\section{Binary silicate melts}

In the case of binary silicate melts, the Temkin model and the extended model described above are identical. Oxide activity data have been obtained for many such systems for large parts of the composition range $\mathrm{MO}-\mathrm{SiO}_{2}$. Methods used include equilibration with a pure metal (Richardson and Webb, 1956) extraction from phase diagrams and emf measurements using $\mathrm{CaO} / \mathrm{ZrO}_{2}$ solid electrolytes.

Activity-composition curves for three binary systems are shown in fig 1 . The form of these $a_{\mathrm{MO}}$ versus $X_{\mathrm{MO}}$ curves is determined by the titration of $\mathrm{MO}$ by added $\mathrm{SiO}_{2}$.

Masson (1965) has shown that polymer models may be used to express the measured activity by writing sets of polymerization equilibria of the form

$$
\mathrm{SiO}_{4}+\mathrm{SiO}_{4}+\mathrm{Si}_{2} \mathrm{O}_{7}+\mathrm{O}^{2-}
$$

$$
\begin{array}{cc}
\mathrm{SiO}_{4}+\mathrm{Si}_{2} \mathrm{O}_{7}+\mathrm{Si}_{3} \mathrm{O}_{10}+\mathrm{O}^{2-} & K_{2} \\
\ldots & \\
\mathrm{SiO}_{4}+\mathrm{Si}_{n} \mathrm{O}_{3 n+1}+\mathrm{Si}_{n+1} \mathrm{O}_{3 n+4}+\mathrm{O}^{2-} & K_{n}
\end{array}
$$

where $K_{1}=K_{2}=\ldots K_{n}$.

For bifunctional (linear) polymerization, this leads to

$$
1 / X_{\mathrm{SiO}_{2}}=2+1 /\left(1-a_{\mathrm{MO}}\right)-1 /\left(1+a_{\mathrm{MO}}[1 / K-1]\right)
$$

and for branched chains (Masson, 1972)

$$
1 / X_{\mathrm{SiO}_{2}}=2+3 /\left(1-a_{\mathrm{MO}}\right)-1 /\left(1+a_{\mathrm{MO}}[3 / K-1]\right) \text {. }
$$

Curves calculated from (5.1 to 5.3) above for linear chains are also shown in fig. 1 and agree well with the experimental data for these systems.

These models do not express self-condensation to form ring or network structures and so are unsuitable, without extension to describe the behaviour of magmas considerably more $\mathrm{SiO}_{2}$-rich than the metasilicate composition.

\subsection{The Toop and Samis (quasi-chemical) model}

An alternative to discrete polymerization reactions is to express the excess free energy of mixing in terms of the formation, not of discrete anions, but of quasi-chemical or virtual species. The proportions of species will again reflect the magnitude of the non-ideality. This approach was introduced by Toop and Samis (1962) who considered the interaction of just three oxo-species

$$
\mathrm{O}^{2-}+\mathrm{O}^{0}=2 \mathrm{O}^{-} \text {. }
$$

Where $\mathrm{O}^{2-}$ represents a «free» oxide ion, not bound as part of the silicate network, $\mathrm{O}^{0}$ is an oxo-bridge $\mathrm{Si}-\mathrm{O}-\mathrm{Si}$ and $\mathrm{O}^{-}$a singly charged oxygen atom also bonded to the cations present.

Allowing simple Temkin mixing, the proportions of the species are thus given by

$$
K=\left(X_{\mathrm{O}^{2-}} \cdot X_{\mathrm{O}}^{-}\right) / X_{\mathrm{O}}^{2-} .
$$




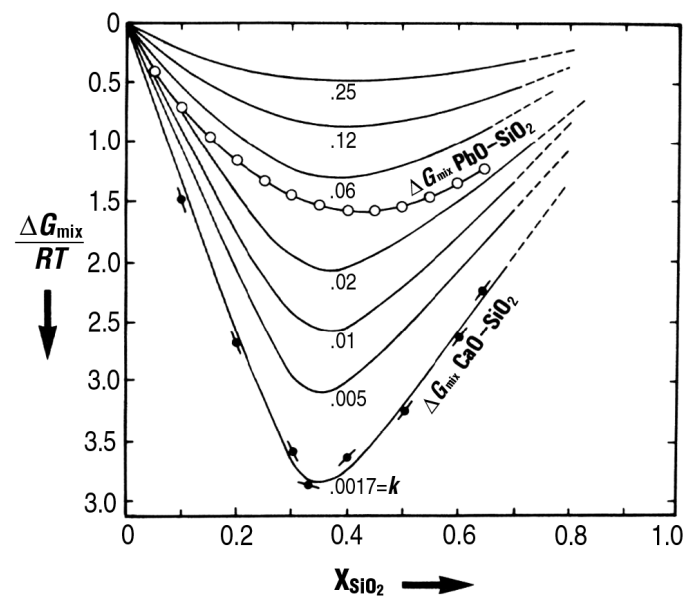

Fig. 3. $\Delta G_{\text {mix }}$ for the systems $\mathrm{CaO}-\mathrm{SiO}_{2}$ and $\mathrm{PbO}-$ $\mathrm{SiO}_{2}$. Data compared with theoretical curves calculated using the Toop and Samis quasi-chemical model (after Toop and Samis, 1962a).

Applying charge and mass balance constraints (Fraser, 1977), $\Delta G_{\text {mix }}$ may be calculated for any bulk composition. Data for the systems $\mathrm{PbO}-$ $\mathrm{SiO}_{2}$ and $\mathrm{CaO}-\mathrm{SiO}_{2}$ are shown in fig. 3 .

\section{Amphoteric oxides}

The mixing properties of binary silicate melts can be expressed well by models which give real insight into the properties of the melts and which have robust predictive power. An assumption of these models is simple Temkin mixing with complete dissociation of the basic oxide into $\mathrm{M}^{2+}$ and $\mathrm{O}^{2-}$ in its standard state. This cannot be universally true and this standard state problem must be considered carefully when comparing different binaries or working in multicomponent systems (Fraser, 1977). This problem is particularly severe in the case of oxides such as $\mathrm{Al}_{2} \mathrm{O}_{3}, \mathrm{Fe}_{2} \mathrm{O}_{3}$ or $\mathrm{TiO}_{2}$ which may contribute structural units to a greater or lesser extent to the «silicate» framework of the melt - as noted above, electrical conductivity measurements indicate that conductivity is ionic and monopolar.

One approach is to allow for amphoteric properties of real oxides - i.e. in which a given oxide component has the ability to react both as a basic and an acidic oxide depending on the overall composition (Fraser, 1975). To express the real ability of oxides to behave as acidic or basic components, the Temkin model must be further extended. The Lux-Flood acid base system defines acid-base behaviour by the reactivity with oxide ion. By extension, amphoteric behaviour is therefore easy to express as can be seen in the case of $\mathrm{Al}_{2} \mathrm{O}_{3}$

$$
\begin{aligned}
& \mathrm{Al}_{2} \mathrm{O}_{3}=2 \mathrm{Al}^{3+}+3 \mathrm{O}^{2-} \\
& \mathrm{Al}_{2} \mathrm{O}_{3}+\mathrm{O}^{2-}=2 \mathrm{AlO}_{2}^{-} .
\end{aligned}
$$

The net effect of adding $\mathrm{Al}_{2} \mathrm{O}_{3}$ to a multivariate melt will be either to consume $\mathrm{O}^{2-}$ or to increase the $\mathrm{O}^{2-}$ activity depending on the bulk composition and the values of $K_{a}$ and $K_{b}$. Similar criteria apply to $\mathrm{Fe}_{2} \mathrm{O}_{3}$ and other altervalent oxides. For example it is well known that at constant $P, T$ and $a_{\mathrm{O}_{2}}$, iron is more highly oxidized in «basic» melts (Fudali, 1965; Paul and Douglas, 1965a,b). The variation in the oxidation state of Fe with bulk melt composition at constant $P, T$ and $f_{\mathrm{O}_{2}}$ has important implication for its partitioning behaviour and for calculations of redox conditions in the Earth.

In the case of $\mathrm{FeO}$, the two amphoteric equilibria are

$$
\begin{array}{cc}
\mathrm{FeO}=\mathrm{Fe}^{2+}+\mathrm{O}^{2-} & K_{b} \\
\mathrm{FeO}+\mathrm{O}^{2-}=\mathrm{FeO}_{2}^{2-} & K_{a}
\end{array}
$$

in which $K_{a}$ is exceedingly small and can be neglected.

In contrast, the two reactions for $\mathrm{Fe}_{2} \mathrm{O}_{3}$ are likely to be of more equal magnitude

$$
\begin{aligned}
& \mathrm{Fe}_{2} \mathrm{O}_{3}=2 \mathrm{Fe}^{3+}+3 \mathrm{O}^{2-} \\
& \mathrm{Fe}_{2} \mathrm{O}_{3}+\mathrm{O}^{2-}=2 \mathrm{FeO}_{2}^{-} .
\end{aligned}
$$

Thus increasing melt basicity indicated by addition of basic oxides $\mathrm{MO}$ stabilizes $\mathrm{FeO}_{2}{ }^{-}$and hence $\mathrm{Fe}^{\mathrm{III}}$ relative to $\mathrm{Fe}^{2+}+\mathrm{O}^{2-}$ and hence $\mathrm{Fe}^{\mathrm{II}}$.

Similar criteria apply to other altervalent oxides and it has been shown that in the melts in the binary systems $\mathrm{Mg}, \mathrm{CaSiO}_{3}-\mathrm{CaAl}_{2} \mathrm{Si}_{2} \mathrm{O}_{8}$ 
and $(\mathrm{Mg}, \mathrm{Ca})_{2} \mathrm{SiO}_{4}-\mathrm{CaAl}_{2} \mathrm{Si}_{2} \mathrm{O}_{8}$ constant $T$ and $f_{\mathrm{O}_{2}}, \mathrm{Eu}^{\mathrm{III}} / \mathrm{Eu}^{\mathrm{II}}$ ratios increase with increasing MO-content (i.e. decreasing $\mathrm{SiO}_{2}$ ) as expected from the above. However importantly, they also increase with increasing $\mathrm{Ca} / \mathrm{Mg}$ ratio. Since melt basicity has been related to Pauling electronegativity (Duffy and Ingram, 1971), the model predicts that with $\mathrm{CaO}$ more basic than $\mathrm{MgO}, \mathrm{Eu}^{\mathrm{III}} / \mathrm{Eu}^{\mathrm{II}}$ ratios in Ca-rich melts should be higher than in Mg-rich liquids at constant $T$, $P, f_{\mathrm{O}_{2}}$ and $X_{\mathrm{SiO}_{2}}$ as is observed experimentally (Morris and Haskin, 1974; Fraser, 1975).

\section{Behaviour of $\mathrm{H}_{2} \mathrm{O}$ and $\mathrm{CO}_{2}$}

The amphoteric behaviour of oxides also has implications for the solubility of $\mathrm{H}_{2} \mathrm{O}$ water in melts. Ignoring unreacted molecular water, the relevant reactions are

$$
\begin{aligned}
& \mathrm{H}_{2} \mathrm{O}+\mathrm{O}^{0}=2 \mathrm{OH} \quad K_{b} \\
& \mathrm{H}_{2} \mathrm{O}+\mathrm{O}^{2-}=2 \mathrm{OH}^{-} \quad K_{a} \text {. }
\end{aligned}
$$

In acid melts, most water will be absorbed to depolymerize the network, forming $\mathrm{OH}$ groups bonded to silicate anions. However in basic compositions, water should dissolve by a different mechanism such as (7.2). In this, $\mathrm{H}_{2} \mathrm{O}$ reacts with oxide ion as an acidic oxide to produce free hydroxyl ions. This mechanism, (Fraser, 1977), has recently been observed by careful MAS NMR observations of quenched $\mathrm{CaMgSi}_{2} \mathrm{O}_{6}$ glasses (Xue and Kanzaki, 2003). The overall solubility will depend on the overall basicity, the values of $K_{a}$ and $K_{b}$ and the stability of the free hydroxide species $\mathrm{Ca}(\mathrm{OH})_{2}$ and $\mathrm{Mg}(\mathrm{OH})_{2}$. The solubility of $\mathrm{S}$ also depends on similar reactions involving $\mathrm{S}^{2-} / \mathrm{SO}_{4}$ equilibria (Fincham and Richardson, 1954; Holzheid and Grove, 2002; O'Neill and Mavrogenes, 2002). Similarly $\mathrm{CO}_{2}$ behaves dominantly as an acidic oxide by the reaction

$$
\mathrm{CO}_{2}+\mathrm{O}^{2-}=\mathrm{CO}_{3}^{2-} \text {. }
$$

Note that $\mathrm{H}_{2} \mathrm{O}, \mathrm{CO}_{2}$ and sulphur all interact with the oxo-species equilibria in molten silicates. Thus, for example, wet melting, or melting in the presence of differing amounts of $\mathrm{CO}_{2}$ or sulphur will not only involve the dissolution of the volatile component, but will perturb the balance of oxo-, and hence silicate, structural species in the silicate melt which are in equilibrium with solid phases on the liquidus. To maintain crystal liquid equilibrium, the effects of the dissolved volatile component must be offset, most usually by the addition of more or less silica. Thus, in moderately acidic melts, $\mathrm{H}_{2} \mathrm{O}$ dissolution occurs dominantly by (7.1) above. Wet melting thus requires addition of $\mathrm{O}^{0}$ (i.e. $\mathrm{SiO}_{2}$ ) to restore the $\mathrm{O}^{-} / \mathrm{O}^{0}$ equilibrium according to eq. (5.6) and wet melting leads to an expansion of the olivine primary phase volume towards silica-rich (andesitic) compositions as will be described below. $\mathrm{CO}_{2}$ has the opposite effect.

\section{Implications of acid-base reactions for silicate crystal-melt phase equilibria}

The acid-base properties of oxides described above may be used to bridge the gap between the experimental and theoretical work which has led to detailed understanding of oxide activities in metallurgical slags on the one hand, and the need for a similar conceptual framework for considering silicate activities and equilibiria on the other.

The results of MAS NMR spectra obtained from silicate glasses and also from high temperature melts allow the identification in low pressure melts and glasses of species with half-lives long in comparison with the measurement technique. Thus, $\mathrm{SiO}_{4}$ tetrahedra can be identified with different linkage states, $Q$ (e.g., Stebbins, 1987). Olivine-like $Q^{0}$ species are isolated tetrahedral groups with no cross links, $Q^{2}$ species are middle groups with pyroxene-like linkages and $Q^{4}$ species are three dimensionally cross-linked.

Successful application of the quasi-chemical model utilizes the excess free energy of mixing to form quasi-chemical species which then mix ideally. This can be applied to relate the NMR data to the oxide activity thermodynamic data by extending the quasi-chemical model of Toop and Samis introduced above. In an early paper, Huggins (1954) referred to basic structural units as «structons» and we can express the compositions 
of silicate structons by an extension of the $Q$-formalism used to interpret NMR spectra. Let each quasi-chemical constituent be represented by $\mathrm{Si}^{i j}$ where $i$ is the number of singly bonded oxygens and $j$ the number of bridging oxygens, then the set of five tetrahedral structons for $\mathrm{Si}$ is ${ }^{40} \mathrm{Si}$, ${ }^{31} \mathrm{Si},{ }^{22} \mathrm{Si},{ }^{13} \mathrm{Si}$ and ${ }^{04} \mathrm{Si}$. The first is an isolated tetrahedron as in olivine and the last a fully crosslinked unit as in quartz.

The Toop and Samis model considers the excess free energy of mixing to arise, as shown above, from the reaction

$$
\mathrm{O}^{2-}+\mathrm{O}^{0}=2 \mathrm{O}^{-}
$$

The quasi-chemical species, $\mathrm{O}^{-}$and $\mathrm{O}^{0}$ of this model may be used to construct silicate species or structons by considering the probability of forming each. These probabilities $P_{i j}$ are thus

$$
\begin{aligned}
& P_{40}=X_{O}^{4-} * 1=X_{O}^{4-} \\
& P_{31}=X_{O}^{3-} \cdot X_{O}^{0} * 4 ! / 3 ! .1 !=4 X_{O}^{3-} \cdot X_{O}^{0} \\
& P_{22}=X_{0}^{2-} \cdot X_{O}^{20} * 4 ! / 2 ! .2 !=6 X_{O}^{2-} \cdot X_{O}^{0} \\
& P_{13}=X_{0}^{-} \cdot X_{O}^{30} * 4 ! / 1 ! .3 !=4 X_{0}^{-} \cdot X_{O}^{30} \\
& P_{04}=X_{O}^{40} * 1=X_{0}^{40} .
\end{aligned}
$$

Within the quasi-chemical model, the structons mix ideally and their proportions can be calculated directly from the proportions of Toop and Samis oxo-species. These are determined by the polymerisation equilibrium constant characteristic of each oxide. Basic oxides like $\mathrm{CaO}$ have a very low value of $K(e . g ., K=0.003$ in fig. 1) and less basic oxides such as $\mathrm{NiO}$, higher values ( $K=46$ in fig. 1$)$. The relationship of these values to electronegativity will be considered elsewhere (Fraser, in prep.).

Silicate crystal-liquid phase equilibrium can be expressed simply using this model.

For example the crystallization of enstatite from a melt is defined by the equilibrium

$$
\mu_{\mathrm{MgSiO}_{3}}(\text { liq })=\mu_{\mathrm{MgSiO}_{3}}(\text { xtal })
$$

and
For true quasi-chemical mixing in the melt, the structon model predicts that ideal mixing of quasi-chemical species should obtain. Thus the activity in the melt is defined as $a_{\mathrm{MgSiO}_{3}}($ liq)= $=X_{\mathrm{Mg}}^{\mathrm{CM}} \cdot X^{22} \mathrm{Si}=6 X^{2} \mathrm{O}^{-} X^{2} \mathrm{O}^{0}$. Note that $X_{\mathrm{Mg}}{ }^{\mathrm{CM}}$ refers to mixing in the divalent cation matrix. As noted above, the recent NMR data of Lee and Stebbins (2003) suggest that it may be necessary to extend the simple Temkin model to consider the mixing of different types of cation in silicate melts and glasses in a more sophisticated way than hitherto. A first approach may be to consider the mixing of cations of different charge separately in different matrices.

A test of this model is available if appropriate values of $K$ are available for a system. Values of the temperature dependence of $K$ are available for the system $\mathrm{FeO}-\mathrm{SiO}_{2}$ (Distin et al., 1971; Masson, 1972). A plot of LnK versus $1 / T$ yields a value of 0.574 at the eutectic temperature of $1455 \mathrm{~K}$. Using this value, the activity of ${ }^{40} \mathrm{Si}\left(\right.$ i.e. $\left.\mathrm{SiO}_{4}\right)$ structons in the melt can be calculated at each temperature. For the eutectic composition at $1455 \mathrm{~K}$, the value is 0.893 . This compares well with the value of $a \mathrm{Fe}_{2} \mathrm{SiO}_{4}$ calculated from the depression of freezing point of 0.882 (Fraser, 1977).

\section{Multi-component systems}

The above model provides a means of relating metallurgical oxide activity measurements to silicate element partitioning and phase equilibrium data. In the earth sciences an outstanding problem is to predict the effects of changing composition or volatile content.

The effects of adding third components to a univariant equilibrium in the system $\mathrm{MgO}-\mathrm{SiO}_{2}$ have been described by Kushiro (1973) for the forsterite-enstatite-liquid equilibrium and the effects of different oxides on this equilibrium are shown in fig. 4.

This equilibrium is expressed in terms of the structon model by the two simultaneous equations

$$
\begin{aligned}
& \mu_{\mathrm{Mg}_{2} \mathrm{SiO}_{4}}^{0}(\text { liq })+R T \ln a_{\mathrm{Mg}_{2} \mathrm{SiO}_{4}}(\text { liq })= \\
& \mu_{\mathrm{Mg}_{2} \mathrm{SiO}_{4}}^{0}(\text { xtal })+R T \ln a_{\mathrm{Mg}_{2} \mathrm{SiO}_{4}}(\text { xtal })
\end{aligned}
$$




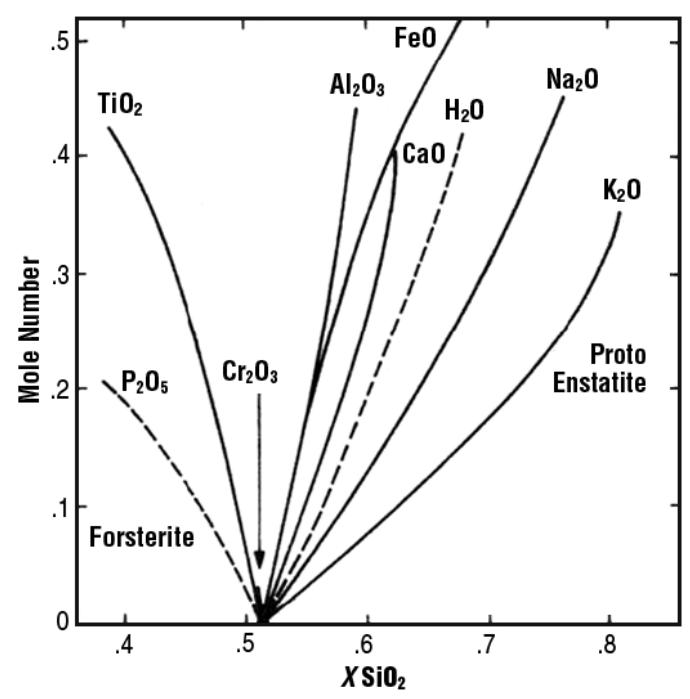

Fig. 4. Effects of different added oxides on the forsterite-enstatite-liquid equilibrium (after Kushiro, 1973).

$$
\begin{aligned}
& \mu_{\mathrm{MgSiO}_{3}}^{0} \text { (liq) }+R T \ln a_{\mathrm{MgSiO}_{3}}(\text { liq })= \\
& \mu_{\mathrm{MgSiO}_{3}}^{0}(\text { xtal })+R T \ln a_{\mathrm{MgSi}_{3}}(\text { xtal }) .
\end{aligned}
$$

The activities of the melt components are given by

$$
\begin{aligned}
& a_{\mathrm{Mg}_{2} \mathrm{SiO}_{4}}(\text { liq })=X_{\mathrm{Mg}}^{2}{ }^{\mathrm{cM}} \cdot X_{\mathrm{Si}}^{40}=X_{\mathrm{Mg}}^{2{ }^{\mathrm{cm}}} \cdot X_{\mathrm{O}}^{4-} \\
& a_{\mathrm{MgSiO}_{3}}(\text { liq })=X_{\mathrm{Mg}}^{\mathrm{CM}} \cdot X_{\mathrm{Si}}^{22}=X_{\mathrm{Mg}}^{\mathrm{cM}} \cdot 6 X_{0}^{2-} X_{O}^{20} .
\end{aligned}
$$

The effect of adding basic or acidic oxides will shift the balance of the forsterite-enstatite-melt equilibrium according to the proportions of ${ }^{40} \mathrm{Si}$ and ${ }^{22} \mathrm{Si}$ structons in the melt. Thus addition of a basic oxide such as $\mathrm{K}_{2} \mathrm{O}$ will increase the proportion of ${ }^{40} \mathrm{Si}$ relative to ${ }^{22} \mathrm{Si}$. Equilibrium is only maintained by a balancing shift towards $\mathrm{SiO}_{2}-$ rich compositions. Conversely addition of an acidic oxide such as $\mathrm{P}_{2} \mathrm{O}_{5}$ will have the opposite effect and move the position of the equilibrium to $\mathrm{SiO}_{2}$ poor values.

The effect of added water in this diagram is basic, but less so than for $\mathrm{Na}_{2} \mathrm{O}$ or $\mathrm{K}_{2} \mathrm{O} . \mathrm{H}_{2} \mathrm{O}$ dissolves in silicate melts with at least two chemical mechanisms in addition to dissolution as molec- ular $\mathrm{H}_{2} \mathrm{O}$, as discussed above. The net effect for these compositions seems to be somewhat basic of neutral so that the forsterite-enstatite equilibrium is shifted to $\mathrm{SiO}_{2}$-rich compositions. This behaviour, with the expansion of the forsterite primary phase volume to $\mathrm{SiO}_{2}$-rich compositions during wet melting is well known as is shown in fig. 5 for the system Di-fo-SiO 2 .

Whereas wet melting leads to silica-rich melt compositions, melting in the presence of $\mathrm{CO}_{2}$ has the opposite effect implying that $\mathrm{CO}_{2}$ is an acidic oxide, consuming $\mathrm{O}^{2-}$ dominantly by the formation of $\mathrm{CO}_{3}^{2-}$. The structon model provides a framework within which a range of properties of silicate melts may be considered. These include redox behaviour, volatile solubility, physical properties and crystal-liquid equilibrium in igneous systems. In order for quasichemical or polymer models based on the Temkin equation to be successfully applied in multi-component systems, it should be remembered that the assumption of full dissociation of the «basic» oxide in the standard state is unlikely to be generally true as pointed out by Fraser (1977). The correct treatment of the behaviour of amphoteric oxides in melts thus requires crosscalibration of the standard states for the different end-member oxide components present.

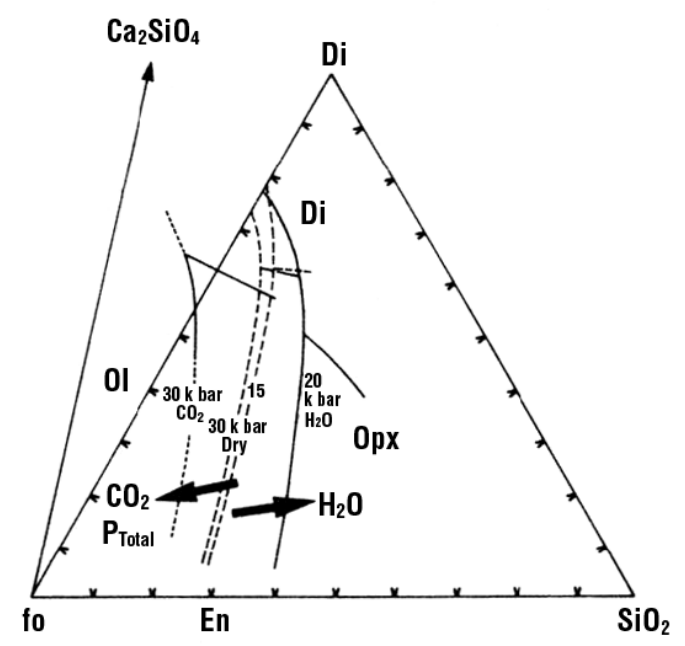

Fig. 5. Phase relations in the system diopsideforsterite-quartz. 


\section{Conclusions}

Metallurgical oxide-activity measurements and the quasi-chemical or polymer theoretical models developed to interpret the variation of oxide activity with composition in binary silicate melts may be used to calculate the proportions of silicate structural units, or structons, in melts. The Lux-Flood acid-base system may be extended to describe the behaviour of amphoteric oxides such as $\mathrm{Al}_{2} \mathrm{O}_{3}$ and $\mathrm{Fe}_{2} \mathrm{O}_{3}$ by the introduction of a second acidic reaction to provide an amphoteric pair for each oxide. The oxidation state of $\mathrm{Fe}$ and other altervalent oxides increases with increasing basicity in response to the stabilization of the acidic reaction of the higher oxidation state.

Application of these models to multi-component silicate melts requires measurement or calibration of the acid-base constants and calibration of the different oxide standard states noted by Fraser (1977) and may require extension of the simple Temkin fused salt model to allow for the separate behaviour of metal ions of different charge recently reported in the NMR data of Lee and Stebbins (2003). This model thus provides a multi-parameter framework for the characterization of the behaviour of melts and melt-solid equilibria which can be fitted using similar methods to those adopted by Ghiorso et al. (2002), or Berman and Brown (1984). An advantage is that the structon model is based on a first-order extension to the regular solution model so that a closer relationship to structural data so that extrapolation may be possible. In addition, the acid-base constants which describe the melt properties are relatable to fundamental chemical parameters such as the optical basicity scale based on the ${ }^{1} \mathrm{~S}_{0} \rightarrow{ }^{3} \mathrm{P}_{1} \mathrm{UV}$ transition proposed by Duffy and Ingram (1971).

\section{REFERENCES}

Asimow, P.D., M.M. HiRschman and E. Stolpe (2001): Calculation of peridotite partial melting from thermodynamic models of minerals and melts, IV. Adiabatic decompression and the composition and mean properties of mid-ocean ridge basalts, J. Petrol., 42, 963-998. BECKETT, J.R. (2002): Role of basicity and tetrahedral spe- ciation in controlling the thermodynamic properties of silicate liquids, Part 1 . The system $\mathrm{CaO}-\mathrm{MgO}-\mathrm{Al}_{2} \mathrm{O}_{3}$ $\mathrm{SiO}_{2}$, Geochim. Cosmochim. Acta, 66, 931-107.

BERMAN, R.G. and T.H. Brown (1984): A thermodynamic model for multicomponent melts, with application to the system $\mathrm{CaO}-\mathrm{Al}_{2} \mathrm{O}_{3}-\mathrm{SiO}_{2}$, Geochim. Cosmochim. Acta, 48, 661-678.

BockRIS, J.O'M. and G.W. Mellors (1956): Electric conductance in liquid lead silicates and borates, J. Phys. Chem., 60, 1321-1328.

Bockris, J.O'M., J.A. KitCHENER, S. IGNATOWICZ and J.W. TomLinson (1952a): The electrical conductivity of silicate melts: systems containing $\mathrm{Ca}, \mathrm{Mn}, \mathrm{Al}$, Discuss. Faraday Soc., 4, 281-286.

Bockris, J.O'M., J.A. KITCHENER and A.E. DAVIES (1952b): Electric transport in liquid silicates, Trans. Faraday Soc., 48, 536-548.

Cripps-Clark, C.J., R. SRIDhar, J.H.E. JefFes and F.D. RICHARDSON (1974): Chain distribution and transition temperatures for phosphate glasses, in Physical chemistry of process metallurgy, edited by J.H.E. JEFFES and R.J. TAIT (Inst. Mining. Met., London).

Distin, P.A., S.G. Whiteway and C.R. MAsson (1971): Solubility of oxygen in liquid iron from 17858 to $19608^{\circ} \mathrm{C}$. New technique for the study of slag-metal equilibrium, Canad. Metall.Quart., 10, 73-78.

DuFFY, J.A. and M.D. INGRAM (1971): Establishment of an optical scale for Lewis basicity in inorganic oxyacids, molten salts and glasses, J. Am. Chem. Soc., 93, 64486454.

EGGLER, D.H. (1974): Effect of $\mathrm{CO}_{2}$ on the melting of peridotite, Carnegie Inst. Wash. Yearbook, 73, 215-224.

Fincham, C.J.B. and F.D. RichaRdSON (1954): The behaviour of sulphur in silicate and aluminate melts, Proc. $R$. Soc., 223A, 40-61.

Flood, H. and T. FöRland (1947): The acidic and basic properties of oxides, Acta Chem. Scand., 1, 952-1005.

FLORY, P.J. (1936): Molecular size distribution in linear condensation polymers, J. Am. Chem. Soc., 58, 18771885.

FLORY, P.J. (1953): Principles of Polymer Chemistry (Cornell University Press).

FrASER, D.G. (1975): Activities of trace elements in silicate melts, Geochim. Cosmochim. Acta, 39, 1525-1530.

FRASER, D.G. (1977) Thermodynamic properties of silicate melts, in Thermodynamics in Geology, edited by D.G. Fraser (D. Reidel Pub. Co., Dordrecht), 303-325.

Fraser, D.G. (2003): Acid base properties, structons and the thermodynamic properties of silicate melts, Geochim. Cosmochim. Acta, 67, A103.

FudALI, R.F. (1965): Oxygen fugacities of basaltic and andesitic magmas, Geochim. Cosmochim. Acta, 29, 10631075.

Gemmell, A., D.G. Fraser and K. Refson (2003): Molecular dynamics simulations of diffusion in a silica melt, Eos, Trans. Am. Geophys. Un., 84 (46), Fall Meet. suppl., abstr. V11D-0528.

GHIORSO, M.S. and R.O. SACK (1995): Chemical mass transfer in magmatic processes, IV. A revised and internally consistent thermodynamic model for the interpolation and extrapolation of liquid-solid equilibria in magmatic systems at elevated temperatures and pressures, Contrib. Min. Petrol., 119, 197-212. 
GHIORSO, M.S., M.M. HiRschmanN, P.W. REINERS and V.C. KRESS (2002): The pMELTS: a revision of MELTS for improved calculation of phase relations and major element partitioning related to partial melting of the mantle to $3 \mathrm{GPa}$, Geochem. Geophys. Sys., 1030

GöTZ, J. and C.R. MASsON (1970): Trimethylsilyl derivatives for the study of silicate structures, Part I. A direct method of trimethylsilylation, J. Chem. Soc. A, 2683-2686.

Guggenheim, E.A. (1952): Mixtures (Clarendon Press, Oxford).

Hildebrand, J.H. and R.L. ScotT (1950): The Solubility of Non-Electrolytes (Publ. Reinhold).

HolzHEID, A. and T.L. Grove (2002): Sulfide saturation limits in silicate melts and their im pli ca tions to core formation scenarios for terrestrial planets, Am. Mineral., 87, 227-237.

HugGins, M.L. (1954): The structure of amorphous materials, J. Phys. Chem., 58, 1141-1146.

KushiRO, I. (1973): Liquidus boundaries between olivine, pyroxene, $\mathrm{CaSiO}_{3}$, and silica polymorphs at 1 atm, Carnegie Inst.-Wash. Yearbook, 72, 497-502.

LEE, S.K. and J.F. STEBbins (2003): The distribution of sodium ions in aluminosilicate glasses: a high-field Na-23 MAS and 3Q MAS NMR study, Geochim. Cosmochim. Acta, 1699.

LENTZ, C.W. (1964): Silicate minerals as sources of trimethylsilyl silicates and silicate structure analysis of sodium silicate solutions, Inorg. Chem., 3 (4), 574-579, doi: 10.1021/ic50014a029.

Lux, H. (1939): «Acids» and «bases» in a fused salt bath: Determination of oxygen-ion concentration, Z. Elektrochemie, 45, 303-309.

MAsson, C.R. (1965): An approach to the problem of ionic distribution in liquid silicates, Proc. R. Soc., 287A, 201-221.

MAsson, C.R. (1972): Thermodynamics and constitution of silicate slags, J. Iron Steel Inst., 210, 89-92.

Moretti, R. and G. Ottonello (2003): Polymerization and disproportionation of iron and sulfur in silicate melts: insights from an optical basicity-based approach, J. Non-Cryst. Solids, 323, 111-119.

MorRIS, R.V. and L.A. HASKIN (1974): EPR measurement of the effect of glass composition on the oxidation states of europium, Geochim. Cosmochim. Acta, 38, $1435-1445$

Mysen, B.O. (1997): Aluminosilicate melts: structure, composition and temperature, Contrib. Mineral. Petrol., 127, 104-118.
Mysen, B.O., D.H. EgGLeR, M.G. Seitz and J.R. HolLOWAY (1976): Carbon dioxide in silicate melts and crystals, Part 1. Solubility measurements, Am. J. Sci., 276, 455-479.

NAVRotsky, A. (1995): Energetics of silicate melts, Rev. Mineral., 32, 121-144.

O’Neill, H. St.C. and J.A. Mavrogenes (2002): The sulfide capacity and the sulfur content at sulfide saturation of silicate selts at $1400^{\circ} \mathrm{C}$ and 1 bar, J. Petrol., 43, 1049-1087.

OTTONELLO, G. (2001): Thermodynamic constraints arising from the polymeric approach to silicate slags: the system $\mathrm{CaO}-\mathrm{FeO}-\mathrm{SiO} 2$ as an example, J. Non-Cryst. Solids, 282, 72-85.

Отtonello, G. (2005): Chemical interactions and configurational disorder in silicate melts, Ann. Geophysics, 48 (4/5), 561-581 (this volume).

Paul, A. and R.W. Douglas (1965a). Ferrous-ferric equilibrium in binary alkali silicate glasses, Phys. Chem. Glasses, 6, 207-211.

Paul, A. and R.W. Douglas (1965b) Ferrous-ferric equilibrium in binary alkali silicate glasses, Phys. Chem. Glasses, 6, 212-215.

RichARDSON, F.D. (1956): Activities in ternary silicate melts, Trans. Farady Soc., 52, 1312-1324.

RichaRDSON, F.D. and L.E. WEBB (1956): Oxygen in molten lead and the thermodynamics of lead oxide-silica melts, Trans. Inst. Min. Metall., 64, C529-C555.

SteBbins, J.F. (1987): Identification of multiple structural species in silicate glasses by Si-29 NMR, Nature, 330, 465-467.

StebBins, J.F., P.F. McMillan and D.B. Dingwell (Editors) (1995): Structure, dynamics and properties of silicate liquids, Mineral. Soc. Am., Rev. Mineral., 32, pp. 616.

Temkin, M. (1945): Mixtures of fused salts as ionic solutions, Acta Phys. Chim. U.R.S.S., 20, 411-420

Toop, G.W. and C.S. SAMIS (1962a): Activities of ions in silicate melts, Trans. Met.-Soc. A.I.M.E., 224, 878-887.

Toop, G.W. and C.S. SAMIS (1962b): Some new ionic concepts of silicate slags, Canad. Met. Quart., 1, 129-152.

WAFF, H.S. and D.F. WEILL (1975): Electrical conductivity of magmatic liquid effects of temperatures, oxygen fugacity and composition, Earth Planet. Sci. Lett., 28, 254-260.

Xue, X. and M. KanZaKi (2003): The dissolution mechanism of water in alkaline earth silicate melts: One view from 1H MAS NMR, Geochim. Cosmochim. Acta, 67, A543. 